\title{
A synthetic-biology reality check
}

\author{
Is the abrupt closure of prominent player Codon Devices an omen for the field?
}

\begin{abstract}
Launched with some fanfare in 2004, Codon Devices of Cambridge, Massachusetts, was touted as a flagship for the industrial applications of synthetic biology, a nascent discipline that applies engineering approaches to the molecular design of biological systems. In late March, however, the company closed its doors.
\end{abstract}

"I'm personally disappointed," says Codon co-founder George Church of Harvard University, who works on gene sequencing and synthesis technology. "It seemed like an opportunity to bring a lot of money into a field that had a lot of promise and I don't think that's hype; I just think that's a matter of time."

Codon Devices was backed by a range of top-drawer venture capitalists. The scientific founders, alongside Church, were Drew Endy, then of the Massachusetts Institute of Technology (MIT) in Cambridge, who was working on the development of small, reusable genetic components known as BioBricks; Jay Keasling of the University of California, Berkeley, who engineers metabolic pathways; and Joseph Jacobson of MIT's Media Lab, who works on creating molecular machinery. The company started out with a two-pronged strategy: to provide synthetic genes and reagents to order, and to partner with other firms to develop synthetic-biology applications.

But having two different balls in play did not work well. In the first of its two target markets there were incumbent competitors - notably DNA 2.0 in Menlo Park, California, Blue Heron Biotechnology of Bothell, Washington, and Geneart, based in Regensberg, Germany - for whom selling synthetic DNA was the core business.

\section{"This is a young,} exciting and dynamic field. It will take time; that's what you would expect."
"They tried to do two really hard things in the same small company - to be a successful manufacturing and service company on the one hand, and to be a high-powered R\&D company," says John Mulligan, Blue Heron's chief scientific officer. "It's super-hard to combine in one small company those two pretty disparate corporate cultures."

Robert Carlson, a principal at Biodesic an engineering and design company in Seattle, Washington - and a former colleague of
Endy's, points to another problem with combining the two approaches: fears about confidentiality. "Inevitably, when Codon partnered with, say, a company pursuing biofuels, any other biofuels company was bound to feel uneasy about shipping designs for genes or genetic circuits off to Codon."

Codon seemed to recognize the problems in its approach. In March 2008, it received a cash infusion of $\$ 31$ million from its existing investors, including such well-connected figures as Vinod Khosla of Khosla Ventures in Menlo Park and Michael Hunkapiller of Alloy Ventures in Palo Alto, California. Three months later, it said it would streamline its business and refocus on applications rather than synthesis. The move may have come too late, says Church. "A lot of our burn rate would be having a sales staff," he explains. "Codon should have stuck with its long-term plan": to provide the "foundational platform" for synthetic biology, as Intel provides a platform for computing.

Still, some analysts are perplexed that Codon's board hasn't explained why the company decided to pull the plug so suddenly. "The lack of explanation as to why Codon
Devices is reported to be 'quietly shutting down' strikes me as very odd," says Steve Aldrich, president of Bio Economic Research Associates in Cambridge, Massachusetts. "I would have thought that the controlling venture investors would be anxious to reassure public markets, which might interpret the abandonment of such a high-profile start-up as a negative judgement on the idea that we would be able to rapidly design, engineer and commercialize biological applications anytime soon."

Drug companies are keen to use synthetic biology to improve drug development, according to Richard Kitney of Imperial College London's centre for synthetic biology, and this raises the question of why the company didn't find a larger concern to buy it up.

Khosla, Hunkapiller, Endy and Jacobson did not respond to requests to comment for this piece. But other scientists say that synthetic biology has a bright future that need not hinge on the fate of a single firm. "This is a young, exciting and dynamic field, and this is one of the companies that tried to make it and failed in a pretty tough environment," says Sven Panke of the Swiss Federal Institute of Technology in Zurich. "It will take time; that's what you would expect."

Indeed, one of the most promising applications of synthetic biology is thought to lie in the development of better biofuels. In 2007, Church launched a separate synthetic-biology biofuels company, LS9, in South San Francisco, with backing from Khosla, among others. Khosla is also an investor in an earlier Keasling start-up, Amyris Biotechnologies of Emeryville, California, which has begun working on biofuels and is developing cheaper antimalarial drugs in partnership with the Paris-based pharmaceutical company Sanofi-Aventis and the San Francisco-based non-profit Institute for OneWorld Health.

These and other competing ventures may have made life more difficult for Codon, which was recruiting biofuels partners. "You've got the combination of many more [start-ups] getting into biofuels and many more players like BP and Shell," says Kitney. "That must have put quite a lot of pressure on Codon Devices." Erika Check Hayden and Heidi Ledford 